
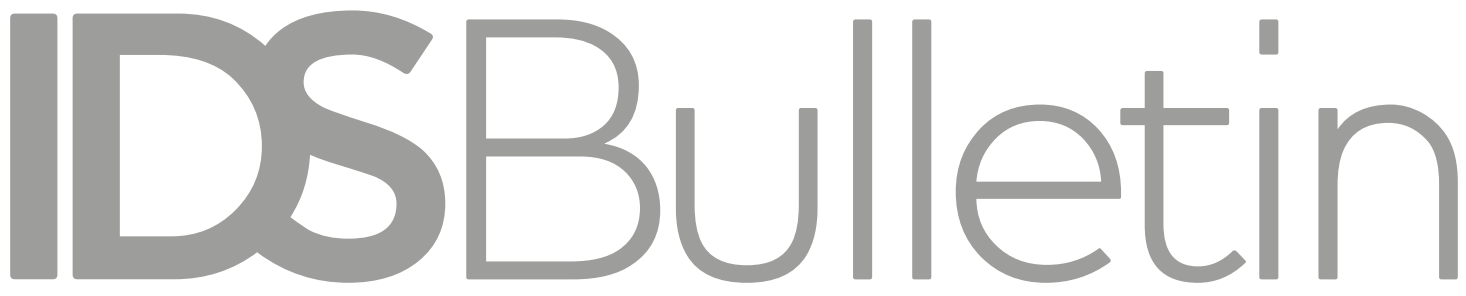

Transforming

Development Knouledge

Volume 49 | Number 2 | March 2018

\title{
ACCOUNTABILITY \\ FOR HEALTH EQUITY: \\ GALVANISING A \\ MOVEMENT FOR \\ UNIVERSAL HEALTH \\ COVERAGE
}

Editors Erica Nelson,

Gerald Bloom and Alex Shankland

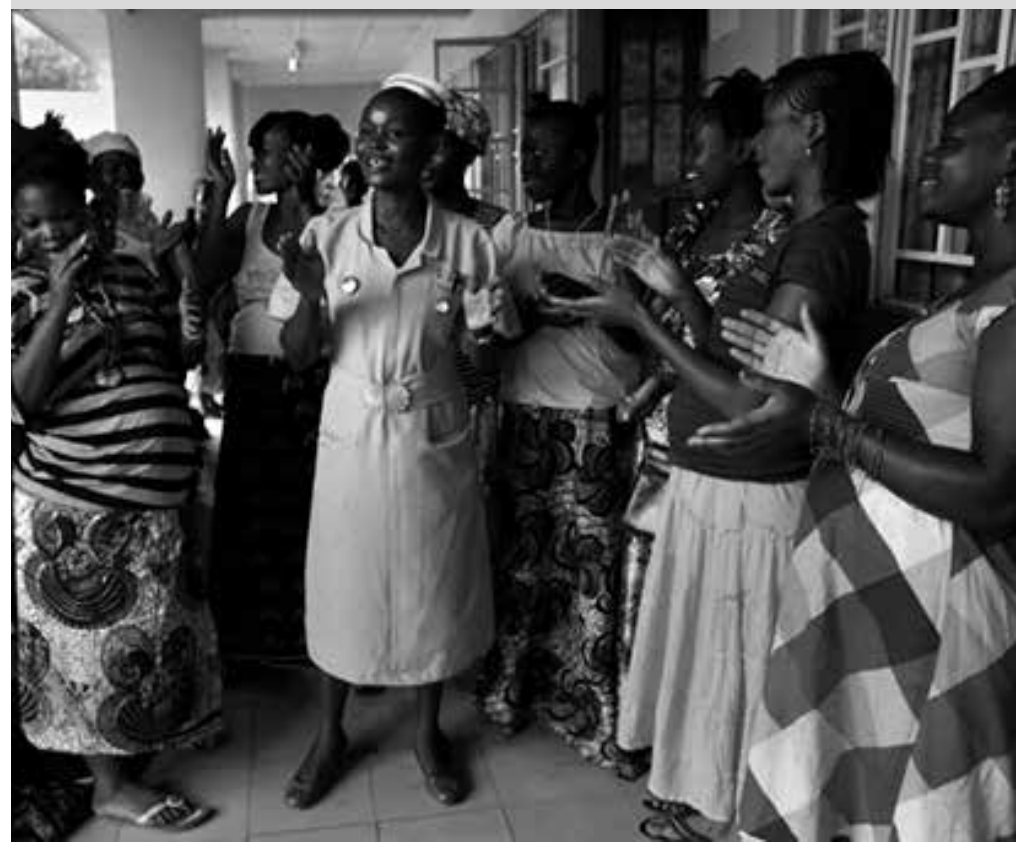


Notes on Article Contributors

Notes on Multimedia Contributors

Foreword

The International Health Partnership for UHC 2030 (UHC2030) Core Team

Introduction: Accountability for Health Equity: Galvanising a Movement for

Universal Health Coverage

Erica Nelson, Gerald Bloom and Alex Shankland

Introduction to Multimedia

Sophie Marsden, Karine Gatellier and Sarah King

Vaishali Zararia, Renu Khanna and Sophie Marsden

Denise Namburete and Erica Nelson

Health Accountability for Indigenous Populations: Confronting Power through Adaptive Action Cycles

Walter Flores and Alison Hernández

Inverted State and Citizens' Roles in the Mozambican Health Sector

Jose Dias and Tassiana Tomé

Accountability and Generating Evidence for Global Health: Misoprostol in Nepal Jeevan Raj Sharma, Rekha Khatri and lan Harper

The Political Construction of Accountability Keywords

Jonathan Fox

Key Considerations for Accountability and Gender in Health Systems in Low. and Middle-Income Countries

Linda Waldman, Sally Theobald and Rosemary Morgan

Gendered Dimensions of Accountability to Address Health Workforce Shortages in Northern Nigeria

Fatima Lamishi Adamu, Zainab Abdul Moukarim and Nasiru Sa’adu Fakai

Reducing Health Inequalities in Brazil's Universal Health-Care System:

Accountability Politics in São Paulo

Vera Schattan Coelho

\section{Making Private Health Care Accountable: Mobilising Civil Society and Ethical}

Doctors in India

Abhay Shukla, Abhijit More and Shweta Marathe

Neglected Tropical Diseases and Equity in the Post-2015 Health Agenda

Emma Michelle Taylor and James Smith 


\title{
Making Private Health Care Accountable: Mobilising Civil Society and Ethical Doctors in India
}

\author{
Abhay Shukla, Abhijit More and Shweta Marathe
}

\begin{abstract}
Though the private sector dominates health care in India, it lacks social accountability and effective regulation. Hence, health activists and health-care professionals have adopted a three-pronged approach of mobilising civil society for patients' rights, networking with ethical doctors towards social responsiveness, and advocating with government for accountable regulation. Health movement strategies adopted mainly in Maharashtra State include organising a regional public hearing in collaboration with the National Human Rights Commission; developing 'Citizen-Doctor Forums'; mobilising citizens around patients' rights through a 'people's poll'; and campaigning for people-oriented regulatory legislation. $A$ national network of doctors is also being developed to promote ethical health care. Key lessons include: identifying patient rights as popular idiom for citizens' mobilisation, relevance of ethical voices within the medical profession to complement social accountability of private health care, potential of moving beyond citizen-doctor adversarial positions to promote accountable health-care options, and placing participatory social regulation on the agenda.
\end{abstract}

Keywords: private health care, social accountability, medical ethics, patients' rights, medical malpractice, dissenting diagnosis, health movement, ethical doctors, Citizen-Doctor Forum, social regulation.

\section{Introduction}

The vision of Universal Health Care (UHC) involving public as well as private health-care providers is gaining traction in countries across the globe. However, the quality of care currently delivered by private health-care providers in low- and middle-income countries (LMICs) remains an issue of concern; two recent Lancet global health series have dealt with this issue in detail. The series on Right Care has emphasised the paradoxical coexistence of failure to deliver needed health-care services (underuse), alongside delivery of unnecessary health-care 
services (overuse), with one of the drivers being market-based systems of health care linked with fee-for-service-type incentive systems for providers (Saini et al. 2017a, 2017b). The Lancet series Universal Health Coverage: Markets, Profit, and the Public Good notes that effective regulation of the private medical sector in LMICs is rare, and governments in most such countries lack capacity to provide effective regulation, contributing to serious concerns about the failure of this sector to deliver the expected social benefit (Morgan, Ensor and Waters 2016; Montagu and Goodman 2016; Horton and Clark 2016).

Within this global context, the private health-care sector in India has grown rapidly since the 1990s, largely linked with inadequate allocation of resources for public health services, and a policy environment viewing health care as a 'business opportunity' while promoting India as a favourable destination for investment in health care (Hooda 2015). Although the private sector dominates the health sector in India with the overwhelming majority of patients accessing it - 80 per cent of outpatient care and 60 per cent of inpatient care (Government of India 2015) - today it is very weakly regulated from the perspective of users' concerns. Although certain frameworks exist for social accountability of public health services in India (Government of India 2005), accountability of the private medical sector is yet to be institutionalised, with frequent complaints of patients' rights being denied.

Here we encounter a paradox, due to the gap between systematically gathered scientific evidence, and widespread, though scattered and often undocumented, social experience. Existing large-scale quantitative surveys related to the health sector in India are focused on public health services and only peripherally deal with private providers, and there is a dearth of systematic studies on the private medical sector. However, individual anecdotes on medical malpractices in this sector are extremely widespread. In this situation, a few exceptional studies such as the book Dissenting Diagnosis (Gadre and Shukla 2016), based on testimonies from 78 doctors across India, stand out due to striking testimonies regarding malpractices in the private medical sector provided by 'whistle-blower' doctors. ${ }^{1}$ By documenting systematically the decline of ethical practices in the medical profession, and the challenges faced by those doctors committed to a 'rational' practice, this book brought to light the current extent of medical malpractice in India's private health-care sector.

The publication of Dissenting Diagnosis and subsequent public responses exemplify how groups of health-care professionals and civil society activists have catalysed social action to demand greater accountability from private medical providers in India. Key issues highlighted in this process include price gauging, over-priced diagnostics, collusion between doctors and diagnostic facilities, extremely high costs of private medical education, and serious concerns regarding quality of care. Innovative social action in Maharashtra State, where this story is based, required the involvement of three major groups of stakeholders: civil 
society organisations, government, and the medical profession. In the following sections, the efforts made by a range of civil society networks and actors for promoting accountability and regulation of the private sector are outlined. These efforts involved a three-pronged strategy of mobilising civil society organisations, networking with ethical, rational doctors, and advocating with the state for regulation of the private medical sector. This article presents the lessons learned through this process and the challenges faced, and offers broader perspectives that have emerged.

\section{SATHI and the health movement: a three-pronged approach}

SATHI (Support for Advocacy and Training to Health Initiatives), a health sector civil society organisation based in Western India, has been contributing to strategies of the health movement for social accountability and responsiveness of private medical providers for the last decade. This strategy has been based on a combination of three complementary approaches: enabling civil society organisations and activists to demand protection of patients' rights in the private medical sector; creating a voice in favour of rational health sector regulation within the medical profession; and engaging with the state government to promote and shape regulation of the private medical sector, with emphasis on social accountability and participation.

Here we need to recognise the unique 'expert' status of the medical profession (perhaps regarded as more exclusive than any other profession), based on monopolies of knowledge (Foucault 1973). Traditionally, key aspects of regulation of medical care have been entrusted to bodies such as medical councils, with the strong expectation that the profession would self-regulate in accordance with the guidance of these councils (Davies 2007). The information asymmetry and associated power relationships between patients and health-care providers are well known, which has implications for the role of social contracts in shaping regulatory processes, particularly in LMIC contexts (Bloom, Standing and Lloyd 2008).

A recent parliamentary committee report in India on the Medical Council of India concluded that 'self-regulation alone may not work because medical associations have fiercely protected their turf, and bodies consisting primarily of members from the same profession are unlikely to promote and protect public interest over their self-interest' (Parliament of India 2016: 18). Given this context, not only to influence formulation of regulation towards social responsiveness, but also to ensure effective implementation of such regulation, sections of doctors who take a public stand in favour of ethics and social accountability in the profession have a critical role to play. This is the justification for SATHI's diversified strategy, which includes developing a network of such 'ethical doctors' ${ }^{2}$ to neutralise the dominant 'anti-regulation' stance of mainstream medical associations, which reflects widespread scepticism regarding regulation amongst ordinary medical practitioners. It seems difficult to ensure regulation of the private medical sector 


\section{Box 1 Key actors in campaign and advocacy processes}

\section{Support for Advocacy and Training to Health Initiatives (SATHI) ${ }^{3}$ is a Maharashtra-based civil society organisation working in the health sector since 1998, which has been a pioneer in the area of promoting community and social action for health rights in India. Through its consistent promotion of participatory action and advocacy together with policy research, SATHI has been able to give some prominence to the issue of patients' rights and regulation of the private medical sector within Maharashtra State, and also at national level.}

Jan Arogya Abhiyan (JAA), the Maharashtra State chapter of the People's Health Movement - India, ${ }^{4}$ is a diverse network of civil society organisations, health activists, doctors, and public health professionals. This coalition has been mobilising people and advocating with decision makers for the promotion of patients' rights in private hospitals and related regulation, for over a decade.

\section{Alliance of Doctors for Ethical Healthcare (ADEH) ${ }^{5}$ is a pan-Indian network of doctors who are committed to promoting ethical and rational health care, and who are critical of widespread medical malpractices linked with the unregulated nature of the private health sector in India.}

without the bringing together of various strands of participatory action. These include social mobilisation for patient rights, and a stand being taken by a section of medical professionals in favour of ethical practice and appropriate regulation. Box 1 briefly describes three key actors SATHI, Jan Arogya Abhiyan (JAA, or the People's Health Movement (PHM) - Maharashtra), and the Alliance of Doctors for Ethical Healthcare $(\mathrm{ADEH})$ - which have played key roles in the campaigns and advocacy processes.

\section{Initiatives to mobilise citizens and facilitate participatory dialogue towards responsive health care}

Maharashtra is the second largest state in India, with a dynamic economy and a highly commercialised, predominantly private health-care sector. Given the lack of regulation of this large and powerful sector, JAA has tried to broaden the technical issue of medical regulation (traditionally an exclusive domain of health-care experts, doctors, and health officials) to include the larger public issue of social accountability. This has been achieved by developing popular discourse around patients' rights.

In India, the regulation of health-care professionals such as doctors (from modern medicine as well as systems such as Ayurveda and homeopathy), dentists, nurses, pharmacists, etc. is carried out through statutory self-regulatory bodies. At the national level, these include 
institutions such as the Medical Council of India, the Central Council for Indian Medicine (CCIM), the Dental Council of India, the Indian Nursing Council (INC), and the Pharmacy Council of India (PCI). There are corresponding professional councils in every state. Such councils are highly prone to 'expert capture'; for example, the nationaland state-level medical councils consist primarily of representatives of doctors and health officials, and these councils are widely known for bias towards protecting medical professionals. They are not known for their responsiveness to patient complaints.

In this context, JAA has adopted the following strategies to promote social accountability of the private medical sector (Phadke et al. 2013): (1) bringing hitherto unexposed malpractices of private hospitals into the public domain, by documenting and publicising such malpractices and organising campaigns for patients' rights. One example of this is the documentation of cases of violations of patients' rights as part of the National Human Rights Commission (NHRG) hearing, described later in this section; (2) challenging the monopoly of medical professionals over regulation, while asserting the role of patients as important stakeholders, during dialogue with decision makers and the medical association; (3) mobilising citizens to demand participatory regulatory systems including grievance redressal mechanisms, as an alternative to bureaucratic command and control type of regulatory systems; ${ }^{6}$ and finally, (4) promoting dialogue and the alliance of active citizens with sections of rational, socially responsive doctors (for example, through the practice of Citizen-Doctor Forums). The JAA's work has prioritised doctors, amongst other possible allies within the medical professions, as they are the most vocal, organised, and politically influential section of health-care professionals in India. These strategies have been developed to engage doctors, as powerful health systems actors, to achieve health policy change.

Certain key actions by JAA in recent years, which exemplify the above-mentioned strategies, are described here as examples.

\subsection{Public hearing organised by the People's Health Movement in collaboration with the National Human Rights Commission of India}

There is growing consensus at international level that all patients have some fundamental rights and that 'patient rights are human rights'. Obligations to the patient by physicians, health-care providers, and the state have taken the shape of Patients' Rights Charters in various contexts. Patients' rights are violated to a substantial extent in a country like India, where the public health-care system is deficient owing to inadequate resources, compounded by the highly commercialised and dominant private health-care sector which lacks effective regulatory frameworks and legally binding provisions for patients' rights. Patients are often denied free, quality health care in the public health system and are forced to seek costly and often irrational care $^{7}$ from private providers. As a result, in India, nearly 50 million people are pushed into poverty every year due to catastrophic expenditure on health care 
(WHO and World Bank 2017). In this setting, basic patients' rights such as the right to emergency care, the right to information, the right to informed consent, and the right to a second opinion are frequently violated.

Given this context, the People's Health Movement - India, of which JAA is an active state constituent, approached the NHRC in 2015, to review the human rights violations of patients in both the public and private health-care sectors. As a result, the NHRC and People's Health Movement - India collaboratively organised a Western region public hearing on the Right to Health Care in January 2016 to make an assessment of human rights violations in public health facilities, private hospitals, and public-private partnership (PPP) health-care arrangements, while drawing attention towards key systemic and policy issues and proposing recommendations for the protection of health rights (NHRC 2015). During the public hearing, testimonies concerning the serious denial of the right to health care were heard by a panel consisting of the Commission members and health experts, in the presence of various state health officials who had to offer appropriate explanations. Consequently, the NHRC issued a set of recommendations to ensure corrective actions (NHRC 2016).

During the hearing, the NHRC did not hear cases related to private hospitals, citing its lack of legal jurisdiction over the private medical sector; however, the Commission took serious note of the failure of the medical councils, lack of regulatory framework for private hospitals, and the absence of a grievance redressal mechanism for patients (ibid.). The NHRC recommended that state governments should either set up a new regulatory body for private hospitals or amend the Medical Council Act to empower medical councils to regulate private hospitals (Medical Dialogues 2016). The public hearing generated significant media attention (The Times of India 2016), while galvanising the health movement on the theme of patients' rights in the private sector. Subsequently, the NHRC has initiated the development of a Patients' Rights Charter, to be applicable to all public and private hospitals. What is clear from this case is the potential of mobilising human rights commissions to engage in the issue of patients' rights, particularly in those LMICs where national human rights commissions are both functional and active.

\subsection{Fostering dialogue through 'Citizen-Doctor Forums'}

Health activists view the current violation of patients' rights in private hospitals as being grounded in systemic distortions linked with the overall commercialisation of health care, and not just the individual profit-motive of private providers. Hence, while developing processes for people-oriented reform of the health sector, it is considered necessary to move beyond adversarial 'patients vs doctors'-type positions, and to develop collaborative dialogue with those sections amenable to reform. SATHI team members, together with other civil society activists, have initiated Citizen-Doctor Forums in the metropolitan cities of 
Mumbai and Pune in Maharashtra, by bringing together active citizens and doctors supportive of rational, ethical health care. The Mumbai Citizen-Doctor Forum has been providing technical and social support to patients who have suffered from serious medical malpractices, ${ }^{8}$ and has expressed public critique of the mishandling of patients' grievances by the Maharashtra Medical Council (MMC), while demanding major reforms within this body. The Pune Citizen-Doctor Forum (PCDF) has created a database of patient-friendly doctors from Pune City based on certain criteria, with the aim of offering lists of such doctors to patients in need. This is accompanied by the development of a web-based platform which can be used by patients to suggest names and provide feedback on doctors whom they have found to be patient-friendly. ${ }^{9}$ The PCDF also periodically organises discussions between citizens and doctors on key policy issues related to health care.

\subsection{The 'Patients' Voice, Citizens' Initiative' campaign}

The 'Patients' Voice, Citizens' Initiative' campaign (Voice of Patients 2017) was launched by JAA in mid-2017, and is centred around a civil society-based public poll in the Pune district of Maharashtra. Citizens were approached to cast their vote on three questions, focused on expected action by the state government related to the regulation of private hospitals; steps to improve the quality of care in public hospitals; and the enactment of legislation to protect patients' rights. Activists reached out to more than 21,000 people at nearly 100 different locations, who agreed to cast their vote. A wide social spectrum was covered in the voting process, ranging from unorganised sector workers to government employees, doctors, nurses, and middle-class professionals. Over 99 per cent of the voters expressed their support for the protection of patients' rights, the regulation and standardisation of private hospitals, along with improved quality of care in public hospitals (Sandilya 2017). The campaign received widespread publicity in the media, and the results were shared with members of the Legislative Assembly, the health minister and the chief minister of the state. JAA activists used the results of this poll for legislative advocacy during the State Assembly session in December 2017, and to convince a large number of elected representatives with regard to the widespread popular support for regulation of private hospitals, and the need for state legislation to ensure such regulation.

This campaign was another unique example of public outreach, which generated widespread popular awareness while documenting dissatisfaction amongst ordinary people regarding private and public health-care services. The idiom 'people's poll' found strong resonance amongst health activists, students, and active citizens who volunteered to conduct the polling process, while the simple act of voting generated awareness amongst the thousands of people who participated. This campaign also sensitised political representatives, who usually consider health care as a non-issue in a country such as India. 


\section{Advocacy with the state for accountable, people-oriented regulation} of the private medical sector

Advocacy for improved accountability of the private medical sector to both patients and citizens is a complex process, with no clear fulcrum for rights-based activism. This is distinct from public health system accountability actors, where there can be a basis for demanding entitlements within legal and policy frameworks at the national level (Phadke et al. 2013). Compared to the somewhat technical approach to regulating private medical providers, the demand to protect patients' rights in private hospitals has broad, popular appeal. Given this context, JAA organised a 'Patients' Rights Convention' in Pune City in July 2009 where citizens and civil society groups presented cases of patients' rights violations in private hospitals. Representatives of the Indian Medical Association (IMA) and the Hospital Owners' Association were invited to respond (Express News Service 2009). When representatives of doctors and hospitals were exposed to organised public opinion under the gaze of the media, they publicly agreed to respect patients' rights. Taking this lead forward, JAA conducted several rounds of discussion with the IMA resulting in the formulation of the consensus 'Joint Charter of Patients' Rights and Responsibilities' (see Box 2), which was released in a joint press conference (The Times of India 2010). Although in the absence of a broader regulatory policy and legal framework, this Charter could not be implemented widely (Phadke et al. 2013), it became an important reference document for future advocacy, helping to reduce the resistance of the medical associations to accepting patients' rights in principle.

In 2010, the Parliament of India passed the Clinical Establishment Act (CEA) to regulate clinical establishments in both the public and private sector (Gazette of India 2010) with certain positive features such as the publication of Standard Treatment Guidelines, mandatory display of rates for services, and the standardisation of rates. In addition, this act created the multi-stakeholder Clinical Establishment Council to agree to both rules and generalised standards in the sector. However, the CEA of 2010 was not sufficiently comprehensive. For example, it did not mention the Charter of Patients' Rights, nor did it offer a grievance redressal mechanism. Furthermore, it created an over-centralisation of standard-setting procedures (Phadke 2010). Given this context, JAA demanded that the state government of Maharashtra should enact its own state-specific CEA by incorporating positive features of the national act, while adding key provisions to protect patients' rights, including grievance redressal mechanisms, and removing certain impractical provisions which would be unfair to doctors. To press for this demand, JAA organised mass demonstrations during Legislative Assembly sessions in 2012 and 2013 (The Times of India 2012), supplemented by advocacy with political representatives and submission of a parallel draft bill to the Maharashtra government. These efforts led the Health Minister of Maharashtra to form a multi-stakeholder drafting committee to prepare a 'Maharashtra Clinical Establishment Bill $^{10}$ (The Times of India 2013). 
Box 2 Key provisions in the 'Joint Charter of Patients' Rights and Responsibilities'

\section{Patients' rights}

1 Right to emergency medical care

2 Right to information and medical records

3 Right to informed consent

4 Right to confidentiality

5 Right to second opinion

6 Rights to respect human dignity and privacy

7 Right to non-discrimination

8 Right to choose alternative treatment if options are available

9 Right to make suggestions/complaints and seek redressal of grievances

10 Compliance with statutory guidelines for biomedical research and clinical trials involving patients

11 Compliance with provision of free beds in charitable trust hospitals for poor patients.

\section{Patients' responsibilities}

1 Provide health-related information

2 Cooperate with doctors during examination, treatment

3 Follow all medical instructions

4 Pay hospital's agreed fees on time

5 Respect dignity of doctors and other hospital staff

6 Never resort to violence against health-care providers.

Source: Samiti (2015).

JAA adopted a two-pronged approach of working within the committee, while also promoting wider social mobilisation for appropriate regulatory provisions (Maharashtra Times 2014). This ensured that key provisions were incorporated in the draft bill including the Charter of Patients' Rights, rate transparency, a district-level multi-stakeholder appellate body with representation to civil society groups, and a grievance redressal mechanism. Provisions for rate standardisation were 
met with stiff resistance from representatives of medical associations in the drafting committee and were not included in the final draft. However, the much-negotiated bill has now been put into cold storage by the state government after a change of political regimes at both national and state levels following the 2014 elections. This has forced JAA to adopt new strategies for social mobilisation in this uphill struggle, some of which have been discussed in Section 3.

\section{Networking doctors to promote ethical health care}

When Dissenting Diagnosis was published (Gadre and Shukla 2016), it was well received by certain sections of doctors and formed the backdrop to the creation of the Alliance of Doctors for Ethical Healthcare (ADEH). A small but significant group of physicians were attracted to the objectives of the ADEH, since it provided a much-needed platform to raise their concerns. These doctors, mostly practising in the private sector, realised that there are many scattered 'voices of conscience' amongst doctors within the sea of commercialisation, which can come together and support each other. Hundreds of doctors from various parts of India have joined ADEH as an emerging national network of doctors committed to promoting ethical and rational health care. Many of them are facing their own survival struggles, since they refuse to join the commercial bandwagon which is based on unethical practices such as kickbacks for patient referral. Senior practising doctors from various states (such as Punjab, Kerala, Maharashtra, West Bengal, Delhi) have signed onto a declaration of the ADEH network, and have begun to take a public stand on key policy issues concerning both the practice of medicine and the conduct of medical professionals.

Some noteworthy interventions by ADEH include initiating public demand for reform and the restructuring of the Medical Council of India; providing technical inputs to the National Pharmaceutical Pricing Authority (NPPA) of India towards fixing the ceiling price of coronary stents and other medical devices; and submitting a range of suggestions to the central government regarding the draft 'National Medical Commission' bill. ADEH is emerging as a distinctive network of doctors articulating an alternative voice from within the medical profession, while working for major reforms in the health-care sector. The ADEH is providing a new platform for medical professionals who choose not to support the conventional lobbying adopted by colleagues associated with doctor-centric mainstream medical associations. By networking with small but socially significant sections of doctors who seek health system reforms, ADEH can complement wider civil society social mobilisation around accountability and the responsiveness of the private medical sector in India today.

\section{Discussion}

Regulation of the private medical sector has generally been viewed from the lens of state-led policy. We argue that this top-down perspective needs to be strongly complemented by a bottom-up view of care delivered by the private sector, based on the experiences of 
patients and citizens concerned with the accountability of care, as well as the concerns of doctors struggling to reconcile ethical medicine with the realities of highly commercialised and market-driven health care. To effectively regulate the private medical sector to ensure its responsiveness to social concerns, state regulation is essential, but needs to be complemented by participatory action.

Participatory initiatives over the last decade in Maharashtra State yield significant lessons about how such processes might be promoted at a national level in a country such as India, which has a large, dominant, heterogeneous, and poorly regulated private medical sector. These experiences can also enrich conceptual health system frameworks, through emerging approaches to accountability in regulatory bodies and the role of participatory, social regulation. Key insights and potential approaches emerging from this experience are outlined in the following discussion.

\subsection{Patients' rights as a popular idiom for mobilisation around the regulation of the private medical sector}

The demand for the protection of patients' rights could be an important fulcrum for social mobilisation around regulation of the private medical sector. Raising demand for including provisions to protect patients' rights in any regulatory framework concerning the private medical sector can help orient regulatory reform around patient-centred accountability (Phadke et al. 2013). Here, the trans-class, multi-sectional nature of demand for patients' rights is a significant strength. Unlike issues related to land, livelihoods, and basic social services which are largely limited to lowerincome sections of the population, the demand for patients' rights is of a cross-cutting nature, which can attract support from sections of the middle class who have significant voice and political leverage.

\subsection{The need for multiple platforms to work with diverse constituencies related to the private medical sector}

Social actors working towards greater accountability and responsiveness of the private medical sector need distinctive organisational forms for engaging with diverse constituencies. JAA works with civil society organisations and citizens, the ADEH works with sections of doctors, while Citizen-Doctor Forums combine both types of members. The SATHI team works centrally with all three groups in collaboration with many other members and organisations. This helps maintain a common thread of accountability and ethics, while developing each platform in concordance with the perspectives and priorities of concerned constituents.

\subsection{Moving from adversarial positions to social concern-based dialogue: Citizen-Doctor Forums}

The experience of Citizen-Doctor Forums exemplifies the relevance of ensuring regular, constructive dialogue between members of the general public and the medical profession. It may be noted that these two constituencies have traditionally often held adversarial positions on private sector regulation. A key lesson is that this sector cannot be reformed by 
the sole efforts of organised citizens or the medical profession; rather, each group needs to engage in greater dialogue with the other to overcome misconceptions, while helping to equalise the traditional power imbalance between lay people and the medical profession. Alliances can be developed around common issues such as accountability of state regulatory frameworks, and the adverse consequences of extreme commercialisation of health care, especially linked with corporate and large for-profit private hospitals. A further medium-term objective of such forums could be preparing the ground for moving towards a system of UHC which would ensure justice for both patients and ethical doctors, by de-commercialising the health-care system overall.

\subsection{The development of voices for ethics within the medical profession as a complement to social accountability}

Advocacy related to regulation of the private medical sector is somewhat unique. Unlike many other issues involving the binary opposition of stakeholders (typically civil society organisations/affected social groups vs the government), in this case there are three major categories of stakeholders. Along with citizens and the state, the private medical profession is another powerful, autonomous stakeholder which decisively influences health sector policy. Hence, any major change is bound to be a complex, triangular process. Since primary resistance to regulation of the private medical sector comes not from the state but from the medical profession, without moderating this resistance, while ensuring elements of participation in the regulatory process, it may not be possible to develop effective regulation. Hence, along with citizen mobilisation, there is an ongoing need to work with the medical profession, towards developing voices for social responsiveness. These voices would include doctors concerned about the negative impacts of gross commercialisation. The involvement of physician advocates can both reshape regulation, by ensuring that the critical concerns of doctors are taken on board, and also helps overcome resistance to regulation from mainstream medical associations.

\subsection{The problematic record of regulation of the private medical sector in} India, with potential for corruption

Studies point to the inadequacy of the existing regulatory architecture concerning the private medical sector in India and other LMICs (Sheikh, Saligram and Hort 2013; Bloom, Henson and Peters 2014; Tangcharoensathien et al. 2008). Regulatory gaps are underpinned by ambivalence in the roles of regulatory organisations, ineffective coordination between regulatory groups, and extensive contestation of regulatory policies by private stakeholders (Sheikh et al. 2013). Other studies have indicated that pursuing traditional approaches to enforce rules through administrative and bureaucratic controls may be inadequate, because they fail to deal with the political economy and the social realities of health care (Bloom et al. 2008; Mackintosh and Tibandebage 2002), emphasising the need for innovative approaches to regulation. Further, during discussions with sections of doctors and hospital owners regarding regulation of their sector, one of the strongest 
objections was concerning the corruption that often accompanied traditional regulatory frameworks in India. State actors entrusted with the regulation of private hospitals might use minor administrative lapses as a pretext for rent-seeking, with the original rationale of regulation being lost. Even ethically practising doctors who were opposed to giving bribes complained of such coercion based on the denial of key sanctions, if the expected 'gratification' was not provided. While this may be an exaggerated view of the seamy side of regulation, it emphasises the need to ensure social accountability of the regulators themselves.

\section{Emerging concepts of participatory social regulation}

Continued contestation of regulation by private actors, and the danger of capture of the regulatory process by powerful elements within and outside the state form the backdrop for re-imagining regulation from a citizen-centric perspective. The current weak regulation of the private medical sector in many LMICs is often linked with minimal political will to regulate this sector, since the private health-care industry often has significant financial and political clout. Weak political will may also be linked to a lack of organised popular demand for accountability of the private medical sector, despite widespread yet diffuse discontent about malpractices. Overall weak accountability of the state for enforcing regulations is an additional barrier to effective regulation.

Hence, unless regulation is buttressed by a social accountability framework and participatory processes, in LMICs like India there is a danger of regulatory capture or ineffective regulation, which would defeat its social objectives. Given the powerful influence exerted by the organised medical sector on health policy, there is a need to ensure such participatory action not only amongst citizens, but also amongst socially responsive sections of doctors, to jointly provide inputs for developing and informing the regulatory framework. Building effective public regulatory frameworks must be complemented by the promotion of a social climate of accountability and patients' rights, while strengthening an ethos of ethical, rational care within the medical profession. The state and its policies do not function in a vacuum, but are deeply embedded in social structures and relationships. Hence, it is highly desirable that health sector transformations linked with state regulation and civil society action be interlinked and mutually reinforcing.

Regulation of the private medical sector has often been looked upon as a bureaucratic function of the state, divorced from issues of patients' rights and accountability of private hospitals to health-care users. However, if we proceed from an understanding that regulation is a form of social accountability, then regulators need to become accountable to health-care users in particular, and citizens in a broader sense. (It may be noted that practically all citizens would be health-care users, or carers for patients at various points in their life.) Hence, patients' and citizens' concerns must be strongly reflected in a regulatory framework, otherwise regulatory bodies might be captured by elites, or may become an additional channel for corruption. In this context, social regulation 
envisages that regulatory design should emerge from participatory processes, while its implementation and oversight is provided by multi-stakeholder bodies. Such social regulation would have three inter-related components: state regulatory bodies, multi-stakeholder oversight and monitoring committees, and technical committees consisting of diverse medical professionals. State regulation would be based on legal frameworks, executive authorities, grievance redressal mechanisms, and inspectors. Multi-stakeholder accountability and oversight bodies including civil society and patients' groups, as well as representatives from the medical profession would monitor the regulatory and grievance redressal processes. The technical elements of self-regulation such as standard treatment protocols would be developed by medical professionals drawn from the public, private, and non-profit sections of health-care providers. This participatory model of social regulation envisions action-oriented approaches to reinvent and democratise regulation, with greater patient and citizen involvement in monitoring of enforcement from a rights-based perspective.

If the stalled processes of regulation of the private medical sector in India are to be accelerated and given a direction which would enable regulatory processes to achieve their core social objectives, then social regulation may be the much-needed dynamo required for the long-overdue transformation of this sector.

\section{Notes}

* The authors would like to acknowledge the contributions by various Support for Advocacy and Training to Health Initiatives (SATHI) team members, especially Dr Arun Gadre and Dr Anant Phadke for ideas reflected in this article. They sincerely appreciate the role played by Jan Arogya Abhiyan (People's Health Movement Maharashtra), the Alliance of Doctors for Ethical Healthcare, and Citizen-Doctor Forums in Mumbai and Pune, in developing various activities which form the basis for this article.

1 We use the term 'whistle-blower' here to describe those clinicians within the medical profession who are privy to information about the unethical practices of fellow clinicians and in private hospitals, and who take the risk of making these unethical practices public.

2 We use the term 'ethical doctor' to describe a doctor who takes a public stand that is critical of widespread malpractices in the medical profession, and who publicly commits to abide by the Code of Medical Ethics as formulated by the Medical Council of India. They are often recognised by their peers for their avoidance of prevalent professional malpractices.

3 www.sathicehat.org.

4 www.phmindia.org.

5 www.ethicaldoctors.org.

6 Nursing Home Acts in various Indian states are examples of traditional regulatory laws, which are outdated, ineffective in achieving regulatory objectives, linked with rent-seeking by inspectors, and which promote corruption. 
7 Irrational care is a deviation from scientific Standard Treatment Guidelines developed by the medical professionals' associations/bodies. Such deviations are generally indulged in for improper material gain.

8 Shreya Nimonkar is one such victim of alleged medical negligence. She was advised to have a hysterectomy by her doctor despite this not being medically indicated, and during the procedure both her ureters got badly damaged, leading to lifelong suffering. Shreya is fighting to get justice through the Maharashtra Medical Council, and she is one of the leading organisers of the Citizen-Doctor Forum, Mumbai.

9 www.medimitra.org.

10 www.ayurvedinstitute.com/Director/CEA_Maharashtra_2014_ final_4th_june_1_pm_Taori..pdf.

\section{References}

Bloom, G.; Henson, S. and Peters, D.H. (2014) 'Innovation in Regulation of Rapidly Changing Health Markets', Globalization and Health 10: 53

Bloom, G.; Standing, H. and Lloyd, R. (2008) 'Markets, Information Asymmetry and Health Care: Towards New Social Contracts', Social Science \& Medicine 66.10: 2076-87

Davies, M. (2007) Medical Self-Regulation: Crisis and Change, Aldershot: Ashgate Publishing

Express News Service (2009) 'First Convention of Patients' Rights Forum Held', The Indian Express, 20 July, http://indianexpress.com/ article/cities/pune/first-convention-of-patients-rights-forum-held/ (accessed 9 January 2018)

Foucault, M. (1973) The Birth of the Clinic - An Archaeology of Medical Perception, trans. by A. Sheridan (1973 ed.), London: Tavistock Publications

Gadre, A. and Shukla, A. (2016) Dissenting Diagnosis: Voices of Conscience from the Medical Profession, New Delhi: Penguin Books India

Gazette of India (2010) 'The Clinical Establishments (Registration and Regulation) Act 2010', Extra Ordinary Gazette Part 2, Section 1, 19 August, New Delhi: Ministry of Law and Justice

Government of India (2015) Key Indicators of Social Consumption in India: Health, NSS 71st Round: January - June 2014, National Sample Survey Office, Ministry of Statistics \& Programme Implementation, Government of India

Government of India (2005) National Rural Health Mission: Meeting People's Health Needs in Rural Areas. Framework for Implementation 2005-2012, New Delhi: Ministry of Health and Family Welfare, Government of India, http://nhm.gov.in/images/pdf/about-nrhm/ nrhm-framework-implementation/nrhm-framework-latest.pdf (accessed 10 January 2018)

Hooda, S.K. (2015) Foreign Investment in Hospital Sector in India: Trends, Pattern and Issues, ISID Working Paper 181, New Delhi: Institute for Studies in Industrial Development, http://isid.org.in/pdf/WP181.pdf (accessed 30 December 2017)

Horton, R. and Clark, S. (2016) 'Comment: The Perils and Possibilities of the Private Health Sector', The Lancet 388.10044: 540-41, 
http://dx.doi.org/10.1016/S0140-6736(16)30774-7 (accessed

2 October 2017)

Mackintosh, M. and Tibandebage, P. (2002) 'Inclusion by Design?

Rethinking Health Care Market Regulation in the Tanzanian

Context', Fournal of Development Studies 39.1: 1-20

Maharashtra Times (2014) 'The Clinical Establishment', 4 May, https://maharashtratimes.indiatimes.com/maharashtra/nashiknorth-maharashtra-news/law/articleshow/34602235.cms (accessed 9 January 2018)

Medical Dialogues (2016) 'NHRC Concludes Hearings; Demands Better Regulation of Private Sector', 8 January, https://medicaldialogues. in/nhrc-concludes-hearings-demands-regulation-of-private-sector/ (accessed 9 January 2018)

Montagu, D. and Goodman, C. (2016) 'Prohibit, Constrain, Encourage, or Purchase: How Should We Engage With the Private Health-Care Sector?', The Lancet 388.10044: 613-21, http://dx.doi.org/10.1016/ S0140-6736(16)30242-2 (accessed 2 October 2017)

Morgan, R.; Ensor, T. and Waters, H. (2016) 'Performance of Private Sector Health Care: Implications for Universal Health Coverage', The Lancet 388.10044: 606-12, http://dx.doi.org/10.1016/S01406736(16)00343-3 (accessed 26 February 2018)

NHRG (2016) Recommendations for the State of Maharashtra/Rajasthan/ Gujarat Emerging from Sessions on 7 January 2016, Regarding Systemic Issues and Cases Studies on Right to Health Care, National Human Rights Commission, http://sathicehat.org/images/news-events/ NHRCRecommendations.pdf (accessed 10 January 2018)

NHRG (2015) Organization of Western Region Public Hearing on Right to Health Care in Public and Private Health Sector by NHRC in Collaboration with FSA, National Human Rights Commission, http://nhrc.nic.in/ JanSwasthyaAbhiyan.htm (accessed 9 January 2018)

Parliament of India (2016) Ninety-Second Report: The Functioning of Medical Council of India, New Delhi: Rajya Sabha Secretariat, Department-Related Parliamentary Standing Committee on Health and Family Welfare, Parliament of India

Phadke, A. (2010) 'The Indian Medical Association and the Clinical Establishment Act, 2010: Irrational Opposition to Regulation', Indian Fournal of Medical Ethics 7.4: 229-32, http://ijme.in/articles/theindian-medical-association-and-the-clinical-establishment-act-2010irrational-opposition-to-regulation/ (accessed 9 January 2018)

Phadke, A.; More, A.; Shukla, A. and Gadre, A. (2013) Developing an Approach towards Social Accountability of Private Healthcare Services, New Delhi: Support for Advocacy and Training to Health Initiatives (SATHI) and Community of Practitioners on Accountability and Social Action in Health (COPASAH), www.copasah.net/ uploads/1/2/6/4/12642634/developing_an_approach_towards_ social_accountability_of_private_healthcare_services_-_sathi.pdf (accessed 9 January 2018)

Saini, V. et al. (2017a) 'Drivers of Poor Medical Care', The Lancet 390.10090: 178-90 
Saini, V.; Brownlee, S.; Elshaug, A.G.; Glasziou, P. and Heath, I. (2017b) 'Addressing Overuse and Underuse Around the World', The Lancet 390.10090: 105-7

Samiti, R.H. (2015) Charter of Patients' Rights and Responsibilities, Pune: Support for Advocacy and Training to Health Initiatives (SATHI), www.sathicehat.org/images/articles-published/non_sathi/Charter_ of_Patients_Rights_and_Responsibilities.pdf (accessed 6 March 2018)

Sandilya, S. (2017) 'Residents Vote for Reforms in Healthcare System', The Indian Express, 2 July, http://indianexpress.com/article/cities/ pune/pune-maharashtra-residents-vote-for-reforms-in-healthcaresystem-4731409/ (accessed 9 January 2018)

Sheikh, K.; Saligram, P.S. and Hort, K. (2013) 'What Explains Regulatory Failure? Analysing the Architecture of Health Care Regulation in Two Indian States', Health Policy and Planning 30.1: 39-55

Tangcharoensathien, V. et al. (2008) Regulation of Health Service Delivery in Private Sector: Challenges and Opportunities, Technical Partner Paper 8, International Health Policy Program, Results for Development Institute

The Times of India (2016) 'New Law Must Regulate Private Hospitals: NHRC', 7 January, https://timesofindia.indiatimes.com/city/ mumbai/New-law-must-regulate-private-hospitals-NHRG/ articleshow/50488698.cms (accessed 5 February 2018)

The Times of India (2013) Activists Upbeat about Committee on Clinical Establishment Act', 9 December, https://timesofindia.indiatimes.com/ city/pune/Activists-upbeat-about-committee-on-Clinical-EstablishmentAct/articleshow/27100454.cms (accessed 9 January 2018)

The Times of India (2012) 'Demand for Improving Health Care Services', 20 December, https://timesofindia.indiatimes.com/city/nagpur/ Demand-for-improving-health-care-services/articleshow/17684290.cms (accessed 9 January 2018)

The Times of India (2010) 'Docs, NGOs Join Hands to Ensure Patients' Rights', 10 February, https://timesofindia.indiatimes.com/ city/pune/Docs-NGOs-join-hands-to-ensure-patients-rights/ articleshow/5553778.cms (accessed 9 January 2018)

Voice of Patients (2017) Voice of Patients, Citizen's Initiative Campaign, www.facebook.com/voiceofpatients/ (accessed 9 January 2018)

WHO and World Bank (2017) Tracking Universal Health Coverage: 2017 Global Monitoring Report, Geneva and Washington DC: World Health Organization/International Bank for Reconstruction and Development/World Bank 
